\title{
Paraplegia
}

\section{Adjustment to Spinal Cord Injury: Stage Theory Revisited}

\author{
S. P. Buckelew, PhD, ${ }^{1}$ R. G. Frank, PhD, ${ }^{1}$ T. R. Elliott, $\mathrm{PhD},{ }^{2}$ J. Chaney, MA, ${ }^{1}$ \\ J. Hewett, $\mathbf{P h D}^{3}$ \\ ${ }^{1}$ Department of Physical Medicine $\mathcal{E}$ Rehabilitation, 501 Rusk Rehabilitation Center, \\ University of Missouri, Columbia, Missouri 65212, ${ }^{2}$ Department of Psychology, Virginia \\ Commonwealth University, Box 2018, Richmond, Virginia 23284, ${ }^{3}$ Department of \\ Statistics, M222 Math Sciences Building, University of Missouri, Columbia, Missouri \\ 65212, USA.
}

\section{Summary}

To better understand adjustment following spinal cord injury (SCI), 106 subjects from two samples $(N=53$ each) were administered the SCL-90-R, a symptom checklist, and the Multidimensional Health Locus of Control scales. Sample 1 subjects were admitted for rehabilitation during 1981 to 1982 and sample 2 subjects were admitted during 1984 to 1986. Sample 2 subjects entered rehabilitation programs more quickly after injury and reported more anxiety, phobic anxiety, and hostility than sample 1 subjects. Within each sample, there was no evidence for a relationship between age or time since injury and health beliefs or psychological distress. This study does not support stage theory for adjustment after catastrophic injury, but does suggest the importance of understanding the impact of social policy changes in adjustment following spinal cord injury.

Key words: Adjustment; Spinal cord injury; Psychology.

Spinal cord injury (SCI) is an infrequent, expensive disability affecting approximately 10000 Americans annually (DeVivo et al., 1980; Young et al., 1982). Physical sequelae of SCI may include impaired motor function, sensory function, bowel and bladder function, and sexual function. These physical symptoms often alter vocational, marital, and social roles. Prior to the second World War, more than $80 \%$ of persons sustaining SCI died within 2 weeks of injury (Guttmann, 1976). With improved medical management, life span expectancies now average 30 years (DeVivo et al., 1980). Suicide, however, is now one of the three leading causes of death following SCI (Geisler et al., 1983; Le and Price, 1982). Consequently, a better understanding of psychosocial factors and adjustment following SCI is critical. 
Historically, adjustment to SCI has been viewed as a sequential staging process involving three to five naturally occurring phases (Guttmann, 1976; Bracken and Shephard, 1980; Rigoni, 1977; Stewart, 1977; Tucker, 1980). For example, Stewart describes a three-stage model of coping and adaptation, including denial, depression, and a 'moratorium' or restitution stage (Stewart, 1977). Implicit to stage theories are the assumptions that depression and prolonged pyschological distress are natural responses, to be expected, and even elicited from patients as a normal grieving process. According to stage theory, passivity among both the rehabilitation patient and the staff is a part of the 'normal' grieving process and should be encouraged. Both of these assumptions have been seriously challenged (Frank, Elliott et al., 1987; Frank, Van Valin et al., 1987; Trieschmann, 1988).

Traditionally, little attention has been paid to demographic variables such as time since injury or age of a person at the time an injury occurred. According to stage theories, time since injury could be a critical factor. Almost all stage theories include a final stage in which restitution or adjustment occurs. Consequently, one would expect less distress the longer the time since injury. Evidence for differences in psychological functioning across time following SCI is equivocal (Frank and Elliott, 1987; Frank et al., 1988; Shadish et al., 1981). From a psychological perspective, age at the time of injury should reflect different developmental phases which could modulate the impact of injury on adjustment. Younger patients have responded with more distress than older patients during chronic illness (Westbrook and Viney, 1982) and following amputation (Frank et al., 1984).

The present study was designed to examine the effect of time since injury and age on adjustment following SCI. Stage theory suggests a possible relationship between time since injury and adjustment. In order to maximise the differences between our groups, an extreme groups design was used to further examine the role of age and time since injury on adjustment and health locus of control measures.

\section{Patients and methods}

Subjects $(N=106)$ consisted of two separate samples $(N=53$ in each $)$ of patients admitted to a university rehabilitation center following SCI. Sample 1 subjects were admitted during 1981 to 1982; sample 2 subjects were admitted during 1984 to 1986 . Verbal consent was obtained for all subjects. Subjects unable to respond in written form were assisted by a trained research assistant.

Sample 1 consisted of 44 men and 9 women, and had a mean age of 30.51 years $(S D=13.05)$. Forty six male and 7 female subjects comprised Sample 2, and averaged $28 \cdot 13$ years of age $(S D=11)$. Physiatrists classified subjects' level of injury. For Sample 1, 32 quadriplegics, 17 paraplegics, 3 cauda equina, and 1 central cord diagnoses were made. Sample 2 consisted of 31 quadriplegic and 22 paraplegic patients. Thus, both parts of the total sample represented the most frequently observed distribution of spinal cord patients (i.e., male and quadriplegic) (Trieschmann, 1988; Kalsbeck et al., 1980). The two samples were compared across age, level of injury, and time since injury. Only the population means for the time since injury variable were significantly different $(t(89 \cdot 3)=$ $-2 \cdot 18, p=0 \cdot 03)$. The means for Sample 1 and Sample 2 were 3.6 and $1 \cdot 7$ years, respectively. 


\section{Measures}

Symptom checklist-90-revised. The symptom checklist-90-revised (SCL-90-R) is designed to assess the presence and degree of psychological distress. Subjects rate 90 symptoms on a scale from 0 to 4,0 being 'not at all' and 4 being 'extremely'. There are nine clinical scales reflecting various types of psychopathology (somatization, obsessive-compulsive, interpersonal sensitivity, depression, anxiety, hostility, phobic anxiety, paranoid ideation, and psychoticism), and three global distress measures, reflecting the degree of symptomatology (Global Sererity Index, Positive Symptom Distress and Positive Symptom Total). Test-retest reliability coefficients for one week range from 0.78 to 0.90 . Internal consistency of the subscales range from 0.77 to 0.90 (Derogatis, 1977).

Multidimensional health locus of control scale. The multidimensional health locus of control scale (MHLC) is an 18-item, 6-point Likert-type scale assessing the orientation of subjects' health locus of control beliefs, including internal, powerful others, and chance factors. The three scales are internally consistent with alpha reliabilities ranging from 0.67 to 0.77 (Wallston et al., 1978).

\section{Statistical analyses}

There were three aspects of the data analyses. First, the means from our two samples were compared on all dependent variables using a two-sample t-test. In situations where the population variances were unequal, the approximation developed by Satterthwaite was employed (Satterthwaite, 1946).

Secondly, four different multivariate anlyses of variance (MANOVA) were conducted within each sample because between sample differences existed in the dependent variables. In order to maximise the differences in age and time since injury, an extreme groups design was used. Using upper and lower quartiles of age (Group $1>37$ years; Group $2<20$ years), two age groups were formed and compared on dependent variables. Dependent variables in the first MANOVA were the three subscales from the MHLC: chance, internal, and powerful others. Dependent variables in the second MANOVA included the nine clinical subscales of the SCL-90-R. The third and fourth MANOVA compared two groups of subjects based on the time since injury variable (i.e., Group $1 \geq 3$ years, Group $2 \leq 0 \cdot 17$ years). Dependent variables were the MHLC subscales and the SCL90-R subscales, respectively.

Thirdly, multiple regression analyses were conducted to evaluate the ability of time since injury, age, and sample membership to predict adjustment following SCI.

\section{Results}

\section{Between sample differences on dependent measures}

Using Satterthwaite's (1946) approximation to $t$, correcting for unequal distribution of variances, the two samples were compared on each dependent variable. There were no significant between group differences on MHLC scores; powerful others 
Table Means and standard deviations of SCL-90-R T scores across samples

\begin{tabular}{|c|c|c|c|c|c|}
\hline \multirow[b]{2}{*}{ Subscale } & \multicolumn{2}{|c|}{ Sample 1} & \multicolumn{2}{|c|}{ Sample 2} & \multirow[b]{2}{*}{ p Value } \\
\hline & $\mathbf{M}$ & $\mathrm{SD}$ & $\mathbf{M}$ & SD & \\
\hline Somatization & $60 \cdot 3$ & $11 \cdot 1$ & $63 \cdot 5$ & $9 \cdot 1$ & $0 \cdot 10$ \\
\hline Obsessive-compulsive & $55 \cdot 2$ & $12 \cdot 9$ & $58 \cdot 8$ & $11 \cdot 9$ & $0 \cdot 14$ \\
\hline Interpersonal sensitivity & $50 \cdot 2$ & $14 \cdot 1$ & $53 \cdot 8$ & $12 \cdot 7$ & $0 \cdot 17$ \\
\hline Depression & $55 \cdot 8$ & $15 \cdot 3$ & $60 \cdot 7$ & $12 \cdot 5$ & 0.07 \\
\hline Anxiety & $50 \cdot 2$ & $15 \cdot 3$ & $56 \cdot 5$ & $13 \cdot 5$ & 0.03 \\
\hline Hostility & $45 \cdot 4$ & $12 \cdot 1$ & $51 \cdot 0$ & $12 \cdot 9$ & 0.03 \\
\hline Phobic anxiety & $47 \cdot 5$ & $13 \cdot 4$ & $53 \cdot 3$ & $14 \cdot 1$ & 0.03 \\
\hline Paranoid ideation & $49 \cdot 4$ & $13 \cdot 6$ & $52 \cdot 7$ & $12 \cdot 6$ & $0 \cdot 20$ \\
\hline Psychoticism & $56 \cdot 8$ & $13 \cdot 2$ & $61 \cdot 6$ & $10 \cdot 7$ & 0.04 \\
\hline
\end{tabular}

$(t(102)=-1 \cdot 07, p=0 \cdot 29)$; chance $(t(102)=-1 \cdot 34, p=0 \cdot 18)$ or internal locus of control measures $(t(102)=-0 \cdot 18, p=0 \cdot 86)$. However, t-scores of clinical SCL-90-R subscales were consistently higher in sample 2 than sample 1 , with differences reaching statistical significance on the anxiety $(t(103)=2 \cdot 24, p=0 \cdot 03)$; hostility $(t(103)=2 \cdot 27, p=0.03)$, phobic anxiety $(t(103)=2 \cdot 15, p=0.03)$ and psychoticism scales $(t(103)=2 \cdot 04, p=0 \cdot 04)$. (See Table).

\section{Multivariate analyses}

Age. MANOVA with two levels of the independent variable, defined by the upper and lower quartile age variable, were calculated using two groups of dependent measures, SCL-90-R scores and MHLC scores. Using Wilke's criterion, the MANOVA for the MHLC scores was non-significant for population 1 $(F(3,23)=1 \cdot 20, p=0 \cdot 33)$ and also for population $2(F(3,18)=2 \cdot 91, p=0 \cdot 06)$. The MANOVA for the SCL-90-R scores was also non-significant for population 1 $(F(9,17)=0.86, p=0.57)$ and for population $2(F(9,12)=2 \cdot 07, p=0 \cdot 12)$.

Time since injury. MANOVA with two levels of the independent variable defined by upper and lower quartiles of the time since injury variable were also calculated with the two groups of dependent variables for each sample. The MANOVA for the MHLC scores was not significant for population $1(F 3,20)=0.44, p=0.73$ or for population $2(F(3,26)=0.50, p=0.69)$. The MANOVA for the SCL-90-R scores was also not significant for sample $1(F(9,14)=1 \cdot 88, p=0 \cdot 14)$ or sample 2 $(F(9,20)=2 \cdot 13, p=0.08)$.

\section{Regression analyses}

Multiple regression analyses were used to determine if time since injury, age, or sample membership predicted psychological distress or health locus of control beliefs. Sample membership was coded as a dummy variable. Age, time since injury, and group membership did not significantly predict psychological distress (Total $\left.\mathrm{R}^{2}=0.05 ; F(3,101)=1 \cdot 85, p=0 \cdot 14\right)$, internal locus of control beliefs (Total $\mathrm{R}^{2}=0.006 ;(F(3,100)=0 \cdot 20, p=0 \cdot 89)$; powerful other health locus of 
control beliefs (Total $\mathrm{R}^{2}=0 \cdot 04 ;(F(3,100)=1 \cdot 37, p=0 \cdot 27)$; or chance health locus of control beliefs (Total $\mathrm{R}^{2}=0.02 ;(F(3,100)=0.69, p=0.57)$.

\section{Discussion}

Contrary to stage control theory, age and time since injury were not related to locus of control or psychological distress measures. Our findings do not support the concept of stages in adjustment following spinal cord injury. In addition, there was no evidence of differences due to age. Alternatively, our efforts may be better directed towards looking within the population of patients who have sustained spinal cord injuries to better understand the characteristics of patients coping well. Subgroups of SCI patients who cope well are more internally focused and less reliant on multiple coping strategies (Frank, Wonderlich et al., 1987). Focused efforts on training cognitive restructuring strategies should be the most useful (Buckelew, in press).

In order to have a large enough sample to examine the TSI and age variables, two samples were to be combined in the present study. These two samples collected at the same university hospital setting did not differ on most dependent and demographic variables. The time since injury, however, was significantly different. This duration could reflect changes in acute medical care, utilisation review, and DRG's which occurred between 1982 and 1984. Patients are now discharged more quickly from acute care and more rapidly admitted for acute rehabilitation. Significant differences on psychological distress measures were also found between our two samples. The 1984 to 1986 sample reported higher levels of hostility, anxiety, phobic anxiety, and psychoticism than the 1981 to 1982 sample. Symptoms on these scales include: 'feeling easily annoyed or irritated', 'feeling fearful', 'feeling afraid to travel on buses, subways, or train', and 'the idea something serious is wrong with your body', respectively. Earlier transitions from acute care to rehabilitation may result in more fears and anxieties, which in turn may alter the rehabilitation course. Changes in health care policy and the impact of such changes on adjustment following spinal cord injury warrant further study. Future longitudinal studies to assess coping strategies and adjustment across time are also needed.

Although negative results cannot disprove a theory, this study revealed little support for stage theories. These theories have been criticised for their lack of empirical support. Our sample was primarily composed of male Caucasian subjects, and appears representative of other SCI samples. Generalisation of these findings to specific populations such as female persons following SCI might be inappropriate. Changes in health care policy and the impact of such changes on adjustment following spinal cord injury warrant further study.

\section{References}

BRACKEN MB, SHEPHARD MJ 1980 Coping and adaptation following acute spinal cord injury: A theoretical analysis. Paraplegia 18:74-85.

BuCKelew SP, BAUMSTARK KE, Frank RG, HewETt JE 1990 Adjustment following spinal cord injury. Rehabilitation Psychology 35:101-109.

DEROGATIS LR 1977 SCL-90R administration, scoring, and procedures manual. Towson, MD: Clinical, Psychometric Research. 
DeVivo MJ, Fine PR, MAETz M, Stover, SL 1980 Prevalence of spinal cord injury: A reestimation employing life tables techniques. Archives of Neurology 37:707-708.

FRANK RG, ElliotT TR 1987 Life stress and psychological adjustment following spinal cord injury. Archives of Physical Medicine and Rehabilitation 68:344-347.

FRANK RG, Elliott TR, BuCKElEw SP, HAUt AE 1988 Age as a factor in response to spinal cord injury. American fournal of Physical Medicine and Rehabilitation 67:128-130.

Frank RG, Elliott TR, CoRcoran JR, Wonderlich SA 1987 Depression after spinal cord injury: is it necessary? Clinical Psychology Review 7:1-20.

Frank RG, Kashani JH, Kashani SR, Wonderlich SA, Umlauf R, Ashikanazi GS 1984 Psychological response to amputation as a function of age and time since amputation. British fournal of Psychiatry 144:493-497.

Frank RG, VAN Valin P, Elliott TR 1987 Adjustment to spinal cord injury: A review of empirical and nonempirical studies. Fournal of Rehabilitation 53:42-48.

Frank RG, Wonderlich SA, Umlauf RL, AshkanaZi GS, Buckelew SP, Elliot TR 1987 Differences in coping styles among persons with spinal cord injury: A cluster analytic approach. Fournal of Consulting and Clinical Psychology 55:727-73.

GEISLER WO, JouSSE AT, WYNNE-JoNES H, BREITHAUPT D 1983 Survival in traumatic spinal cord injury. Paraplegia 21:364-373.

GuTTMANN L 1976 Spinal cord injuries: Comprehensive management and research 2nd ed. Blackwell Scientific Publications, Oxford.

KALSBECK WD, MCLAURIN RL, HaRris BS, Miller JD 1980 The national head and spinal cord injury survey: Major findings. Fournal of Neurosurgery 53:519-53.

LE CT, PRICE M 1982 Survival from spinal cord injury. Fournal of Chronic Diseases 35:487-492.

RIGONI HC 1977 Psychological coping in the patient with spinal cord injury. The total care of spinal cord injuries. Little and Brown, Boston, p. 299-307.

SATTERTHWAITE FW 1946 An approximate distribution of estimates of variance components. Biometrics Bulletin 2:110-114.

SHADISH WR, HiCKMAN D, ARRICK MC 1981 Psychological problems of spinal cord injury patients: Emotional distress as a function of time and locus of control. Fournal of Consulting and Clinical Psychology 49:297.

STEWART TD 1977 Coping behavior and the moratorium following spinal cord injury. Paraplegia 15:338-342.

TRIESCHMANN RB 1988 Spinal cord injuries: Psychological, social, and vocational rehabilitation 2nd ed. Demos Publications, New York.

TUCKER SJ 1980 The psychology of spinal cord injury: Patient-staff interaction. Rehabilitation Literature 41:114-120.

Wallston KA, Wallston BS, De Vellis R 1978 Development of the multi-dimensional health locus of control (MHLC) scales. Health Education Monographs 6:160-170.

WESTBROOK MT, VINEY LJ 1982 Age and sex differences in patients' reactions to illness. Fournal of Health and Social Behaviour 24:313-324.

Young JS, BuRns PE, Bowen AM, McCuTchen R 1982 Spinal cord injury statistics. Good Samaritan Medical Center, Phoenix, USA. 